\title{
Annual reproductive rates of Weddell seals in eastern Antarctica from 1973 to 2000
}

\author{
Sam Lake ${ }^{1,2, *}$, Harry Burton ${ }^{2}$, Richard Barker ${ }^{3}$, Mark Hindell ${ }^{4}$ \\ ${ }^{1}$ Institute of Antarctic and Southern Ocean Studies, University of Tasmania, Private Bag 77, Hobart, Tasmania 7001, Australia \\ ${ }^{2}$ Australian Antarctic Division, Channel Highway, Kingston, Tasmania 7050, Australia \\ ${ }^{3}$ Department of Mathematics and Statistics, University of Otago, PO Box 56, Dunedin, New Zealand \\ ${ }^{4}$ Antarctic Wildlife Research Unit, School of Zoology, University of Tasmania, Private Bag 05, Hobart, Tasmania 7001, Australia
}

\begin{abstract}
This study is based on mark and re-sight observations of Weddell seals Leptonychotes weddelli at the Vestfold Hills $\left(68^{\circ} \mathrm{S}, 78^{\circ} \mathrm{E}\right)$, which form a considerable time series (1973 to 2000) pertaining to Prydz Bay in eastern Antarctica. We use multi-strata modeling to estimate annual rates of reproduction and survival whilst taking into account annual and breeding state-specific re-sight probability. Inter-annual variation in both the proportion of females producing pups and the proportion of pups surviving juvenile years reveals the indefinite outcome of each reproductive opportunity for this species of the high Antarctic. In contrast, the relatively high and stable survival rates of breeding females lead to long life span and a spreading-out of reproductive bouts so that individuals sample a number of environments and, given environmental uncertainty, increase the probability of reproducing in a good season when pups are more likely to survive. Lack of evidence for costs of reproduction suggests that Weddell seals prudently select years for reproduction to conserve energy by pre-empting unsuccessful attempts. We propose terminating pregnancy is the Weddell seal's primary physiological mechanism to endure and buffer fluctuations in the environment. The time-series of reproductive rates signals ecosystem change. From 1973 to 2000, annual reproductive rates ranged from 53 to $88 \%$. More recent (1990s) low reproductive rates were not linked to El Niño Southern Oscillation (ENSO) events compared to earlier decades.
\end{abstract}

KEY WORDS: Weddell seal $\cdot$ Ecosystem monitoring $\cdot$ Antarctic $\cdot$ Reproductive rate $\cdot$ Mark and re-sight $\cdot$ MARK

Resale or republication not permitted without written consent of the publisher

\section{INTRODUCTION}

Climate change is a major concern in Antarctic ecosystems. In recent years, the El Niño Southern Oscillation (ENSO) has shown increasing frequency and intensity of warm (El Niño) events (Watkins \& Simmonds 2000) and now the role of ENSO forcing is well documented for physical parameters in the Southern Ocean (Kwok \& Comiso 2002). Other large-scale physical phenomena seem to be changing in response to greenhouse gases and ozone depletion; the Southern Annular Mode, for example (Watkins \& Simmonds 2000). Such change in the physical environment necessarily affects resident species. However, continuous or regular observations over long time intervals (years and decades) are required to characterize such changes, given natural, high levels of background oscillation (White \& Peterson 1996, Turner 2004).

In this context, long-term studies of land-based (and thus readily accessible) marine predators are extremely valuable. In Antarctica, long time-series observations include Weddell seals Leptonychotes weddelli at both the Vestfold Hills $\left(68^{\circ} 33^{\prime} \mathrm{S}, 78^{\circ} 15^{\prime} \mathrm{E}\right)$ and McMurdo Sound in the Ross Sea $\left(77^{\circ} 44^{\prime} \mathrm{S}, 166^{\circ} 30^{\prime} \mathrm{W}\right)$ (Green et al. 1995, Cameron \& Siniff 2004); also Adelie penguins Pygoscelis adeliae in the Ross $\mathrm{Sea}_{\text {; }}$ and southern fulmars Fulmarus glacialoides, snow petrels Pagodroma nivea and emperor penguins Aptenodytes 
forsteri at Terre Adélie $\left(66^{\circ} 30^{\prime} \mathrm{S}, 141^{\circ} 01^{\prime} \mathrm{E}\right.$ ) (Woehler et al. 2002). Monitoring single-predator populations has potential to show changes over time in demographic rates, which are in themselves quantitative measures of population status. As part of a suite of parameters from various populations, the same time series may provide 'snap-shots' of the state of the environment. Ultimately, simultaneous interpretation of multiple time series could provide a basis for ecosystem models (Constable et al. 2003).

This approach to ecosystem monitoring is conceptually focused on the predator's 'perspective' of the environment (Fraser \& Hofmann 2003). Nevertheless, there are many examples where Antarctic predator time series are congruent with large scale physical phenomena (e.g. Whitehead et al. 1990, Testa et al. 1991, Croxall et al. 2002, Fraser \& Hofmann 2003, Jenouvrier et al. 2003 , 2005). In the Southern Hemisphere, it is common for signals of reduced productivity to coincide with El Niño events (Trillmich \& Ono 1991). One of the first studies to propose such a link cited a reproduction time series from Weddell seals in McMurdo Sound (Testa et al. 1991). A decade later, scientists documented ENSO forcing of physical parameters in the Southern Ocean (Kwok \& Comiso 2002). It is this type of inference, later confirmed by clear and convincing observations, that led Chavez et al. (2003) to conclude that physical regime shifts in the ocean may even be best determined by monitoring marine organisms.

Weddell seals at the Vestfold Hills have been monitored by tag and re-sight since 1973 (Green et al. 1995). Typically, the species gives birth to a single pup and breeds (births and lactates) in colonies in an annual pulse. The proportion of reproductively mature (parous) females that produce pups in any specific year (reproductive rate) has already been recognized as highly variable and a potentially sensitive indicator of maternal condition and thus foraging success (Siniff et al. 1977, Croxall \& Hiby 1983, Testa \& Siniff 1987, Testa et al. 1990, 1991, Hastings et al. 1999). Also referred to as breeding probability, reproductive rate combines mating, conception, delay, implantation, gestation, birth, and survival until pups are tagged as neonates 3 to $14 \mathrm{~d}$ old. To evidence the state of the environment, it makes sense to monitor vital rates that vary through time and are likely tied to environmental conditions via energetic constraints.

In the past, quantifying reproduction has been problematic. Early reports used only a simple method, estimating the proportion of females in breeding state based on a ratio of parous females sighted with and without pups. Those studies recognized the potential for bias because females with pups remained on the ice surface near-continually and thus had higher re-sight potential than females in non-breeding state (Testa et al. 1990). Now, multi-strata modeling methods exist that quantify reproductive rate with $\mathrm{CI}$, whilst accounting for inter-annual and breeding state-specific variation in re-sight and survival probabilities (Nichols et al. 1994). Lake (2007) and Hadley et al. (2007) both use these methods to estimate reproductive rate of Weddell seals. Here, we use multi-strata models to estimate survival and reproductive rates of Weddell seals at the Vestfold Hills (Lake 2007) and compare the time series with Hadley et al.'s (2007) results for Weddell seals at McMurdo Sound.

Multi-strata models can pertain to costs of reproduction; costs of reproduction are the energetic trade-off of producing a pup and may include lower probability of surviving and/or reproducing the following year (Stearns 1992). Hadley et al. (2007) found evidence of $3 \%$ lower survival the year after reproduction and inferred Weddell seal life history on that basis. We use the independent data set from the Vestfold Hills to validate their conclusions. Costs to future breeding probability are also important to evaluate because the presence or absence of those costs reveals the temporal window over which reproductive rate is determined.

In summary, this study uses multi-strata models to quantify survival and reproduction of Weddell seals marked and re-sighted at the Vestfold Hills from 1973 to 2000. We evaluated costs of reproduction with regard to life history strategies and the potential for reproductive rate to be used as a temporally precise indicator of foraging success. Survival and reproductive rates in themselves are quantitative measures of the status of the population. With sufficient knowledge, the time-series can be used to detect change in specific aspects of the Antarctic marine environment.

\section{MATERIALS AND METHODS}

Tag and re-sight program. For this study it was a requirement that each parous female have permanent marks or a series of marks that were readily identifiable and readable, and that did not alter the long term behaviour of the seal such that its chances of survival or re-sight were different from the norm. To this effect, all female Weddell seals encountered with pups at the Vestfold Hills were tagged in the webbing of both hind flippers each year from 1973 until 2000, except in 1997 when there was no tagging or re-sighting of seals (Table 1). Most were tagged with Dalton Jumbo Rototags, which have low rates of loss (Cameron \& Siniff 2004). Exceptions were in the initial years of study, when other types of tag were trialed, and some pups were released with only 1 tag. In total, 3 different types of tag were used to mark adult females. These were (1) aluminum tags, which were small and difficult to 
Table 1. Leptonychotes weddelli. Number of known-age (KA) and unknown age (UKA) females newly marked and parous each year in Long Fjord and the Tryne area, and the total number of parous females marked and re-sighted. KA animals were marked at birth whereas UKA animals were marked usually as parous females. Parous is defined as sighted at least once in breeding state

\begin{tabular}{|c|c|c|c|c|c|c|}
\hline Year & $\begin{array}{l}\text { Long } \\
\text { KA }\end{array}$ & $\begin{array}{l}\text { Fjord } \\
\text { UKA }\end{array}$ & $\begin{array}{c}\text { Tryn } \\
\text { KA }\end{array}$ & $\begin{array}{r}\text { e area } \\
\text { UKA }\end{array}$ & $\begin{array}{l}\text { Total } \\
\text { new }\end{array}$ & $\begin{array}{c}\text { Total } \\
\text { sighted }\end{array}$ \\
\hline 1973 & 0 & 123 & 0 & 11 & 134 & 134 \\
\hline 1974 & 0 & 97 & 0 & 85 & 182 & 225 \\
\hline 1975 & 0 & 1 & 0 & 0 & 1 & 62 \\
\hline 1976 & 0 & 0 & 0 & 0 & 0 & 40 \\
\hline 1977 & 0 & 1 & 0 & 0 & 1 & 57 \\
\hline 1978 & 0 & 93 & 0 & 41 & 134 & 186 \\
\hline 1979 & 0 & 52 & 0 & 66 & 118 & 233 \\
\hline 1980 & 2 & 26 & 1 & 24 & 53 & 120 \\
\hline 1981 & 2 & 31 & 0 & 34 & 67 & 164 \\
\hline 1982 & 3 & 31 & 2 & 45 & 81 & 188 \\
\hline 1983 & 5 & 24 & 1 & 50 & 80 & 261 \\
\hline 1984 & 4 & 8 & 0 & 1 & 13 & 137 \\
\hline 1985 & 3 & 6 & 0 & 14 & 23 & 137 \\
\hline 1986 & 1 & 6 & 0 & 22 & 29 & 157 \\
\hline 1987 & 14 & 9 & 1 & 7 & 31 & 179 \\
\hline 1988 & 3 & 9 & 1 & 19 & 32 & 171 \\
\hline 1989 & 9 & 4 & 7 & 15 & 35 & 184 \\
\hline 1990 & 14 & 11 & 1 & 1 & 27 & 163 \\
\hline 1991 & 4 & 3 & 5 & 3 & 15 & 154 \\
\hline 1992 & 11 & 7 & 7 & 9 & 34 & 161 \\
\hline 1993 & 13 & 8 & 0 & 5 & 26 & 142 \\
\hline 1994 & 13 & 0 & 4 & 7 & 24 & 153 \\
\hline 1995 & 14 & 4 & 0 & 10 & 28 & 140 \\
\hline 1996 & 20 & 15 & 7 & 38 & 80 & 180 \\
\hline 1997 & 0 & 0 & 0 & 0 & 0 & 0 \\
\hline 1998 & 14 & 11 & 4 & 11 & 40 & 167 \\
\hline 1999 & 16 & 2 & 8 & 11 & 37 & 173 \\
\hline 2000 & 12 & 10 & 3 & 18 & 43 & 177 \\
\hline Total & 178 & 591 & 52 & 547 & 1368 & 4326 \\
\hline
\end{tabular}

read ( $\mathrm{n}=1200)$, (2) plastic Allflex tags, which were large and had low retention rates $(\mathrm{n}=600)$, and (3) plastic Dalton Jumbo Rototags, which were big enough to read and also had high retention rates ( $\mathrm{n}=$ 20 900) (Cameron \& Siniff 2004). Dalton Jumbo Rototags were used from 1974 onward and exclusively after 1980.

Weddell seal breeding season is approximately 2 mo long, from October to December each year. Our aim was to conduct 3 surveys of the Vestfold Hills study area per breeding season. The study area on the coast of Prydz Bay was bounded by the Sörsdal Glacier to the south, McCally Rocks to the north, the continental land mass to the east and the fast-ice edge to the west (Fig. 1). Females in the main colonies in Long Fjord and the Tryne area were re-sighted both during surveys and pup tagging sessions. Ground searches were conducted throughout fjords and bays for individuals and smaller groups. Where possible, helicopters were used to locate seals on areas of fast ice offshore of the land mass. Once a group's location was recorded from the air, researchers returned to the site by ground vehicle. Each seal encountered was checked for tags and if present, then records were made of tag colour, tag number, seal sex, association with pup, and gridsquare location (resolution $0.65 \mathrm{~km}^{2}$ ).

Timing of the first survey each year varied due to logistical constraints. Similarly, effort tagging and resighting varied from year to year due to personnel and logistics (Green et al. 1995). In 1973 and 1974, 316 parous females were tagged (Table 1). Between 40 and 60 of those females were re-sighted per year over the next 3 yr (1975 to 1977) and tagging methods were refined accordingly. More than 500 parous females were marked in the next 5 yr (1978 to 1983), by which time the majority of the population had been tagged and less than 40 parous females per year required marking subsequently in the program. From 1980, females marked as pups began recruiting into the breeding population. In summary, the dataset consisted of 1368 parous females of which 1138 were marked as adults.

Data analysis. Multi-strata models use encounter histories of individual seals to quantify the probability of encountering individuals in a given breeding state. Whereas standard encounter histories code presence or absence of individuals each breeding season, multistrata encounter histories categorise presence into different levels of breeding state and in this way describe the pattern of breeding for each individual over time. Thus, breeding is modeled as an annually variable phenotypic trait, with each female changing breeding state over time analogous to moving between physically discrete areas. Importantly, the model expresses the probability of encounters allowing for the uncertain state of animals when they were not re-sighted.

Typically, mark and re-sight models divide the probability of encountering an individual in terms of (1) the probability that an animal survived and remained in the study area between samples $i$ and $i+1\left(\phi_{i}\right)$, and (2) the probability that an animal was encountered during sample $i$, conditional on its being alive and in the study area at the time of the sample $\left(p_{i}\right)$. Multi-strata models include a third parameter $\left(\psi_{i}^{s t}\right)$, representing the probability that an animal alive and in state $s$ at time $i$, and which survives the interval between samples $i$ and $i+$ 1 , is in state $t$ at the time of sample $i+1$ (Nichols et al. 1994). We define state $s$ as breeding and state $t$ as nonbreeding. In the base model, breeding probability follows a first-order Markov process in that the probability of breeding at time $i+1$ depends on breeding state at time $i$. Therefore, reproductive rate is defined as the probability of being in state $s$ at time $i+1$, conditional 


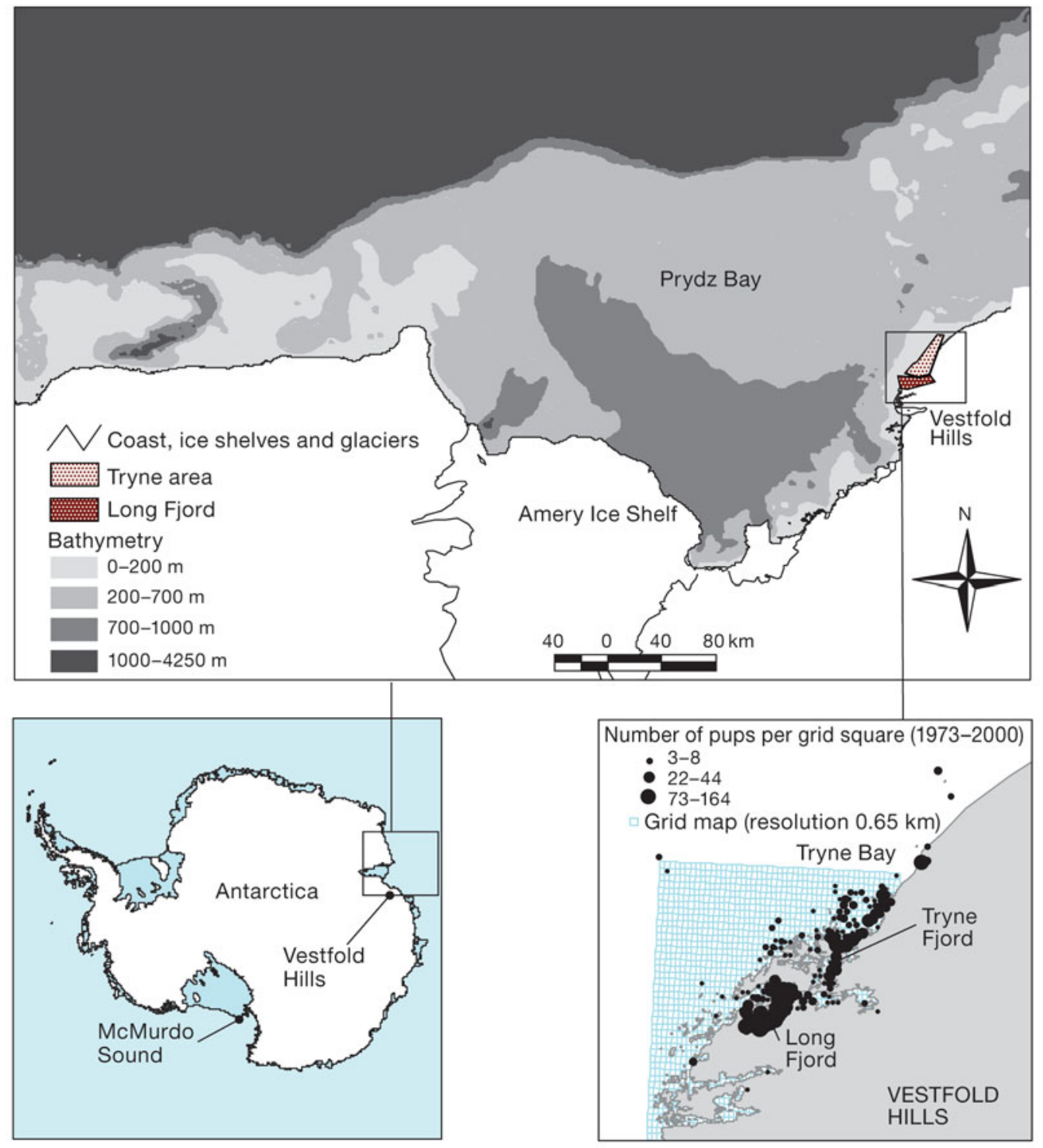

Fig. 1. Leptonychotes weddelli. Mark and re-sight study area at the Vestfold Hills. Top panel shows the study area in relation to Prydz Bay (bathymetry indicated by shading). Bottom left panel shows the study area in the context of the Antarctic continent and in relation to the other mark and re-sight study at McMurdo Sound. Bottom right panel details the distribution of breeding sites observed at the study area in relation to the grid square map by which locations are recorded in the field

on surviving from time $i$ to $i+1$. Importantly, these methods estimate breeding probability as a function of breeding state the previous year; reproductive rate is the probability of non-breeding animals breedingand breeding animals breeding again —in consecutive years.

Model structure. We developed a set of models a priori that evaluated each variable of interest using nested models. We began by determining the best model for re-sight rates, then survival, then reproductive rate, consistent with the order in which these parameters are conditioned. Prior to evaluating terms, we ascertained that the full model $\phi$ (first $\times$ time $\times$ area $\times$ state) $p$ (time $\times$ area $\times$ state $\psi \psi($ time $\times$ state $)$ had 300 identifiable parameters, which was $13.7 \%$ of the effective sample size of 4112 observations and, thus, was considerably over-parameterised. To reduce the number of parameters, a base model was adopted in which survival depended on additive effects, i.e. $\phi$ (first + time + area + state) $p$ (time $\times$ area $\times$ state $) \psi($ time $\times$ state). The additive base model had 184 parameters and an Akaike's Information Criterion incorporating deviance and number of parameters, corrected for sample size (AICc, Burnham \& Anderson 1992) reduced by 104.3 units (Table 2); thus, regarded as a collection, there was no support for interaction terms 
and the additive form of the survival model was used as a base model for evaluating terms.

Models were compared on the basis of the observed deviance and AICc. In general, smaller deviance and AICc indicated the term improved model fit and a difference in AICc $<-2$ or $>2$ indicated significant effect. Akaike model weights $\left(w_{i}\right)$ were used to assess the most likely configurations. Multi-strata models often have multi-modal likelihood functions, so a simulated annealing algorithm incorporated in Program MARK (www.cnr.colostate.edu/ gwhite/mark/mark.htm) was used with different starting values to find the global maximum.

Covariates. The dataset included all parous (reproductively mature) females tagged at the Vestfold Hills. Most of these females were marked as adults with pups, rather than as pups, so they were of unknown age. Since females with pups were marked preferentially and at random, we assumed that the sample was representative of all age groups in the breeding population. The area used for breeding was specified for each individual because there were separate groups of Weddell seals within the Vestfold Hills. Area was treated as a time invariant covariate because Weddell seals tend to be faithful to each of these areas for breeding (Green et al. 1995).

In the model for re-sight rates $(p)$, it was known a priori that re-sight effort varied over time and between Long Fjord and the Tryne area. Hence the re-sight model was stratified by time and area and only the term for breeding state was evaluated. Evaluating this term tested for different re-sight probabilities in different breeding state.

In the model for survival probability $(\phi)$, parameters for temporal variation were evaluated to test for interannual variation in survival rates. A term for area was included to control for different degrees of survival and also fidelity to the breeding areas (emigration). A term for breeding state was evaluated to test for survival costs of reproduction. We included an indicator variable to distinguish between females that were marked in the current year and those marked in previous years because, considering reproductive rate as a summary of the behaviour of site-faithful individuals, estimates should be independent of transient seals. In this context, transient is defined as seals that suckled a pup in the Vestfold Hills area, but did not integrate into 1 of the 2 groups of females that repeatedly occupied the area for breeding. All observations of marked, parous females were included in the dataset and the term for first and subsequent years tagged and parous was specified to account for transient seals or seals that failed to retain new tags.

In the model for reproductive rate $(\psi)$, parameters for inter-annual variation were evaluated to test for changes over time in the proportion of females with associated pups. A term for breeding state was evaluated to test for reproductive costs of breeding the previous year. Area and years since tagging were not included as covariates in the model for reproductive rate because our specific interest was obtaining a time series representative of the population. Furthermore, whilst there may have been fine-scale heterogeneity associated with these variables, interpretation of that heterogeneity in reproductive rate would have been limited because most females were tagged as adults of unknown age and history.

Describing effect size. Individual- and time-specific effect sizes were estimated using the logit link function and linear models (Neter et al. 1990). Thus effect sizes were reported as exp ( $\beta 2)$, i.e. the amount by which the odds of e.g. survival are multiplied for a 1 unit change in the explanatory variable, e.g. breeding state. An odds ratio of 1.0 was no effect. An odds ratio of 1.1 indi-

Table 2. Model-fitting summary, where interaction effects $(\times)$ and main effects $(+)$ of various terms in the models of survival $(\phi)$, re-sight $(p)$ and breeding probability $(\psi)$ were quantified with regard to Akaike's Information Criterion, corrected for sample size (AICc), number of parameters (Npar), deviance and weight of support $\left(w_{i}\right)$ for the model referred to in the text by model number (\#)

\begin{tabular}{|c|c|c|c|c|c|c|}
\hline \# & Model & $\mathrm{AICc}$ & $\Delta \mathrm{AICc}$ & Npar & Deviance & $w_{i}$ \\
\hline 1 & $\phi($ First + Time + Area + State $) p($ Time $\times$ Area + State $) \psi($ Time $)$ & 11859.79 & 0 & 107 & 6158.66 & 0.624 \\
\hline 2 & $\phi($ First + Time + Area + State $) p($ Time $\times$ Area + State $) \psi($ Time + State $)$ & 11860.80 & 1.011 & 108 & 6157.57 & 0.376 \\
\hline 3 & $\phi($ First + Time + Area $) p($ Time $\times$ Area + State $) \psi($ Time $\times$ State $)$ & 11877.14 & 17.35 & 131 & 6125.10 & 0.000 \\
\hline 4 & $\phi($ First + Time + Area + State $) p($ Time $\times$ Area + State $) \psi($ Time $\times$ State $)$ & 11879.20 & 19.42 & 132 & 6125.03 & 0.000 \\
\hline 5 & $\phi($ First + Time + Area + State $) p($ Time $\times$ Area $) \psi($ Time $\times$ State $)$ & 11884.15 & 24.37 & 131 & 6132.11 & 0 \\
\hline 6 & $\phi($ Time + Area + State $) p($ Time $\times$ Area + State $) \psi($ Time $\times$ State $)$ & 11898.03 & 38.24 & 131 & 6145.99 & 0 \\
\hline 7 & $\phi($ First + Time + Area + State $) \mathrm{p}($ Time $\times$ Area $\times$ State $) \psi($ Time $\times$ State $)$ & 11898.80 & 39.01 & 184 & 6032.10 & 0 \\
\hline 8 & $\phi($ First + Time + State $) p($ Time $\times$ Area + State $) \psi($ Time $\times$ State $)$ & 11923.55 & 63.77 & 131 & 6171.51 & 0 \\
\hline 9 & $\phi($ First + Time + Area + State $) p($ Time $\times$ Area + State $) \psi($ State $)$ & 11932.98 & 73.19 & 83 & 6282.16 & 0 \\
\hline 10 & $\phi($ First + Area + State $) p($ Time $\times$ Area + State $) \psi($ Time $\times$ State $)$ & 11980.46 & 120.67 & 108 & 6277.23 & 0 \\
\hline 11 & $\phi($ First $\times$ Time $\times$ Area $\times$ State $) p($ Time $\times$ Area $\times$ State $) \psi($ Time $\times$ State $)$ & 12003.13 & 143.35 & 300 & 5874.39 & 0 \\
\hline
\end{tabular}


cates that the odds increased by $10 \%$. In this way, the effect of each variable was described prior to conversion from the logit scale and independent of the level of other variables. Lack of surveys in 1997 was incorporated in the survival model by specifying a double (2 yr) time interval from 1996, and taking the square root of the 1996 estimate as the average rate for both 1996 and 1997.

Qualifiers: tag loss and emigration. Apparent survival rates are reported uncorrected for tag loss or emigration. For these reasons, the probability of surviving from year to year could have been underestimated, especially in the initial years of the program, when tags were newly inserted, seals had fewer tags, and various types of tag were being trialed. Throughout the program, attempts were made to replace lost tags, especially in Long Fjord, where there was greater re-sight effort. Retagging was done often by surprise, rather than using physical restraint, and so a thorough check of the flippers was not made prior to tagging. Some animals did eventually have 3 or 4 tags. Not every tag was read at each re-sight occasion because that was difficult if the animal was active and not necessary to identify individuals. These incomplete records of tagging status make it impossible to define the precise date that each tag went missing and thus calculate rates of tag loss. For Weddell seals at McMurdo Sound, the probability of loss of single Jumbo Rototags has been estimated to be 0.001 to 0.05 per year and the rate of loss may have increased after several years (Cameron \& Siniff 2004).

\section{RESULTS}

Combined, the best 2 models (\#1 and \#2, Table 2) received $100 \%$ of the support (combined $w_{i}=1.000$ ). Both models had additive effects of first capture, time, area and state on survival probability, and re-sighting rates that varied in parallel between the 2 breeding states but that otherwise differed over time with the pattern of temporal variation in re-sight rates differing among areas. In the model receiving majority support $\left(\# 1, w_{i}=0.624\right)$ the transition probability between breeding states was just time-dependent. In the second best model $\left(\# 2, w_{i}=0.376\right)$ the transition probability was also dependent on previous breeding state. As the combined model weights were less than 0.001 for all remaining models (\#3 through \#11), our data provide no support for interactions between effects of first capture, time, area and state on survival probabilities; no support for an interaction effect of breeding state on time and area in re-sighting probabilities; and no support for the interaction effect of time on breeding state with regard to breeding probability. Lower-ranking models are considered below, where appropriate, to quantify the effect of each specific term by nested models.

\section{Re-sight probability}

Re-sight rates differed between breeding and nonbreeding state (\#4 and \#5). The odds ratio of 3.12 (95\% CI 1.38 to 7.60 ) indicates odds of re-sighting breeding animals were from 1.4 to 7.6 times higher than nonbreeding animals, which translated to approximately $21.9 \%$ greater average probability of re-sighting females when they were in breeding state.

It was known, a priori, that search effort varied over time and area. Thus these terms with interaction effects were included in the base structure of the resight model. Long Fjord females (in breeding state) had several years of re-sight rates less than $80 \%$ and then high, relatively constant, probability of re-sight post 1986 for the rest of the study (Fig. 2, top). In the Tryne area, re-sight rates were more variable, often less than $60 \%$ and exceeding $80 \%$ in only 3 yr (Fig. 2, bottom).

\section{Survival probability}

The odds ratio with $95 \% \mathrm{CI}$ of newly tagged breeders surviving (\#4 and \#6, Table 2) was 0.55 (CI: 0.43 to 0.70 ), which translates to an average $11.3 \%$ (constant on the logit scale) lower apparent survival in the first year compared to subsequent years tagged and parous. Different rates of apparent survival in newly tagged and parous seals, compared to established breeders, could have been due to different rates of tag loss or emigration as well as real differences in rates of survival.

The odds of animals in the Tryne area surviving (\#4 and \#8, Table 2) was 0.60 (CI: 0.52 to 0.70 ) times that of animals in Long Fjord. This translates to an average $7 \%$ lower apparent survival in the Tryne area. Again, this could have been due to different rates of permanent emigration or different rates of tag replacement, as alternatives to real differences in survival.

The temporal trend was for relatively low and variable survival rates in the first few years of the program (Fig. 3). Considering that prior to 1980 many animals were newly tagged (Table 1) and that various types of tags were being trialed, temporal variation in apparent survival at that stage was most likely due to tag loss as opposed to real shifts in survival rates. Post 1982, survival rates were relatively high and stable.

Regarding the term for breeding state ('state') in the survival model (\#3 and \#4, Table 2), despite the differ- 


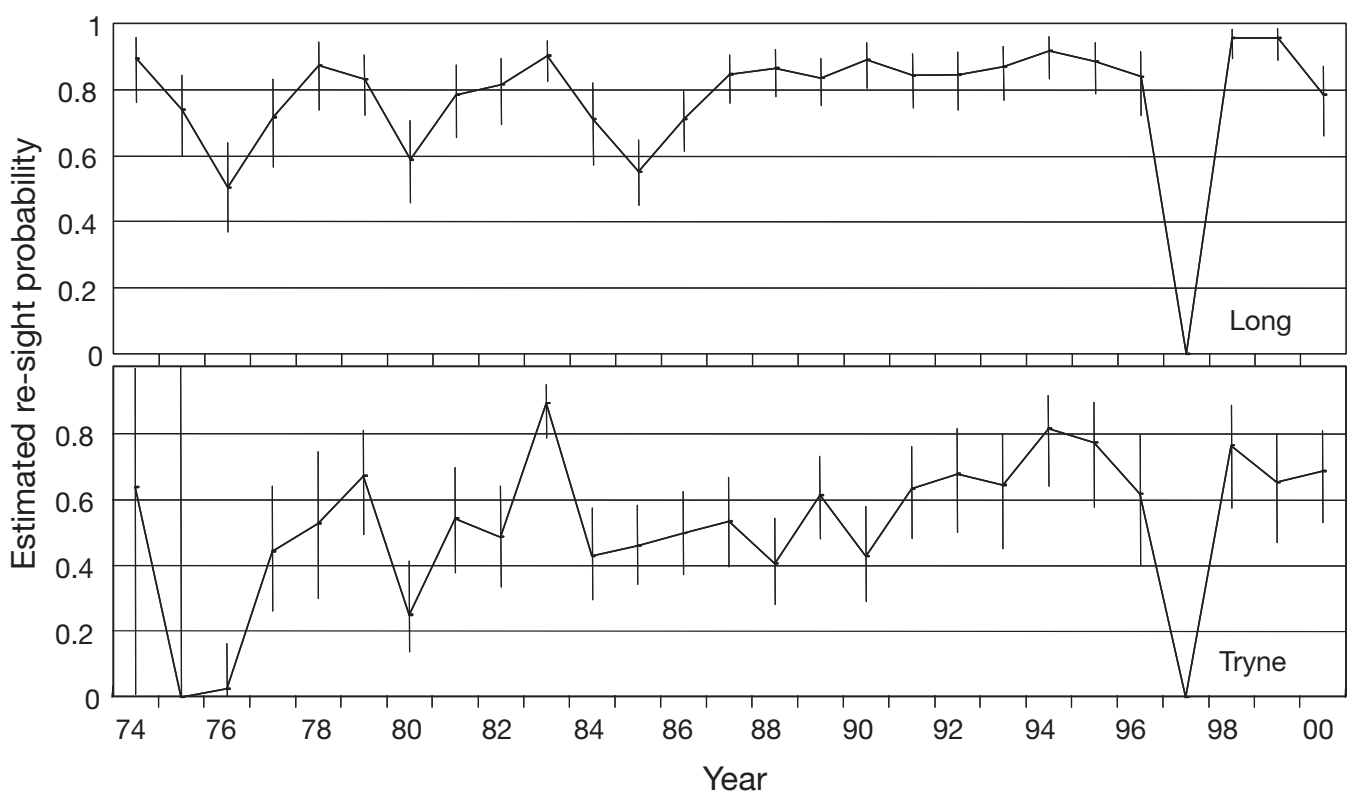

Fig. 2. Leptonychotes weddelli. Re-sight probability of parous females in breeding state in Long Fjord (top) and the Tryne area (bottom) with upper and lower 95\% CI as estimated by the most parsimonious model, $\phi$ (first + time + area + state) $p$ (time $\times$ area + state) $\psi$ (time). The probability of re-sighting was approximately $22 \%$ lower (constant on the logit scale) when the individuals were in non-breeding state

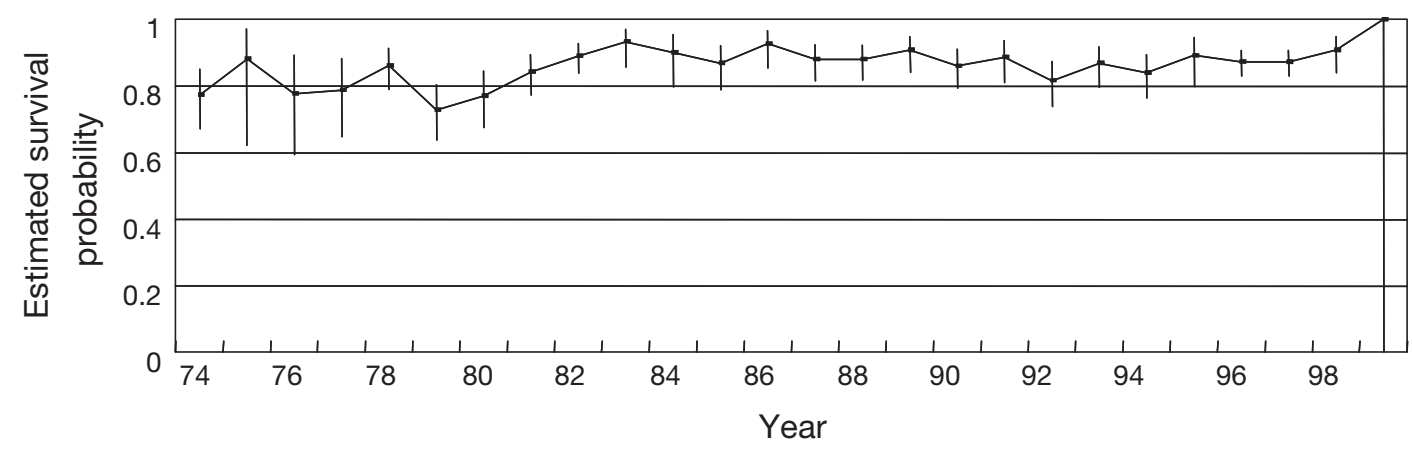

Fig. 3. Leptonychotes weddelli. Survival probability of established, parous females in Long Fjord with upper and lower $95 \%$ CI as estimated by the most parsimonious model, i.e. $\phi$ (first + time + area + state) $p$ (time $\times$ area + state) $\psi$ (time). The following terms had significant, additive effects on probability of apparent survival: newly tagged breeder $(-11 \%)$, breeding in the Tryne area $(-7 \%)$. Breeding state had no effect. Apparent survival rates may have been determined by tag loss, rate of retagging, emigration or real mortality

ence in AICc being 2.06, the change in deviance between these nested models was very small (0.07), indicating that the addition of state to survival probability makes little difference to the fit of the model. By way of confirmation, the odds ratio was close to 1 (1.04), with CI either side of parity ( 0.77 to 1.17$)$. These $\mathrm{CI}$ indicate that the effect of breeding activity could be anywhere from a $23 \%$ reduction to a $17 \%$ increase in survival probability. The term for breeding state was retained in the base model for a conservative set of model comparisons because the term had minimal effect on model fit.

\section{Breeding probability}

In the model parameterising breeding probability, the interaction term between breeding state and time was rejected (\#2 and \#4, $\Delta \mathrm{AICc}=18.4$, Table 2). The term defining previous breeding state was not significant (\#1 and \#2, $\triangle \mathrm{AICC}=1.01$, Table 2). Whilst the model including the term ranked second and was weighted as reasonably likely, the odds ratio $(0.88$, which translates to an effect size of more than $10 \%$ ) had CI either side of parity (0.70 and 1.11) and the top ranking model did not include this variable. We con- 


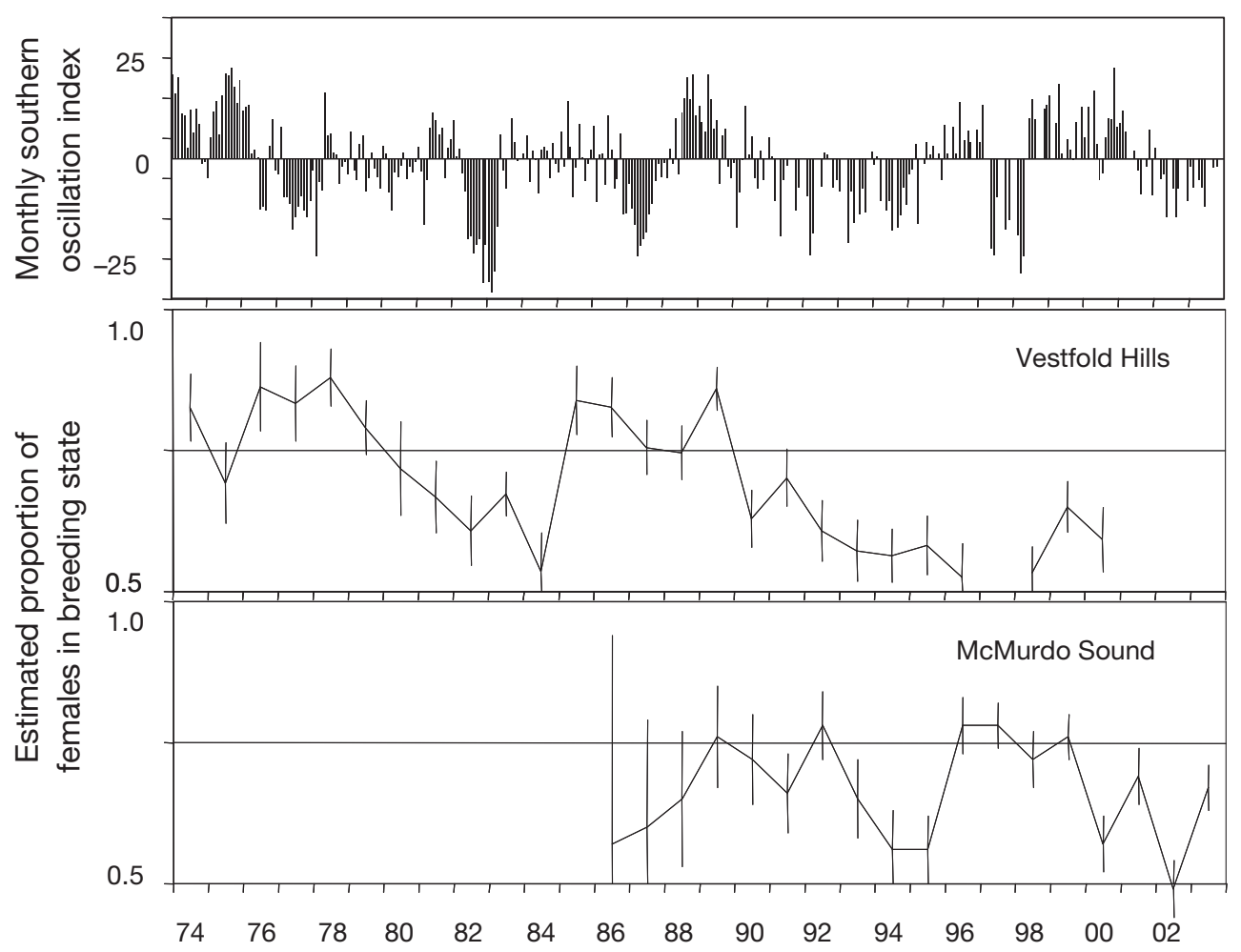

Fig. 4. Leptonychotes weddelli. Probability of parous females being in breeding state, with upper and lower 95\% CI, estimated using the most parsimonious model for Weddell seals at the Vestfold Hills, i.e. $\phi$ (first + time + area + state) $p$ (time $\times$ area + state) $\psi$ (time), compared with the annual probability of Weddell seals being in breeding state at McMurdo Sound (Hadley et al. 2007) and monthly anomalies of the Southern Oscillation Index (SOI). SOI data from the Australian Bureau of Meteorology were the standardised anomaly of the mean sea level pressure difference between Tahiti and Darwin

clude that, across all age groups of breeding females, there was no clear evidence for fecundity costs of reproduction.

The term for temporal variation in breeding probability was strongly supported $(\triangle \mathrm{AICc}=-72.18)$. Across all years of study, breeding probability averaged $70 \pm$ $12 \%$ (mean $\pm \mathrm{SD}$ ), ranging from 53 to $88 \%$. The temporal pattern was for high rates of reproduction in the 1970s, low rates in the early to mid 1980s, high rates in the mid to late 1980s, and then low rates of reproduction throughout the 1990s (Fig. 4).

\section{DISCUSSION}

That reproductive events are precarious for Weddell seals is evident from the magnitude of inter-annual variation in the proportion of females producing pups ( $70 \pm 12 \%$, Fig. $4 ; 67 \pm 9 \%$ Hadley et al. 2007), and also the magnitude of inter-annual variation in the proportion of pups surviving their first year of life $(43 \pm 21 \%$, S. Lake unpubl. data; $43 \pm 11 \%$, Hastings et al. 1999; $55 \pm 21 \%$, Cameron \& Siniff 2004). Conversely, the rates of survival of parous females are higher and less variable (Fig. 3) (Hadley et al. 2007), although specific details vary between studies. At the Vestfold Hills, apparent survival rates were higher in Long Fjord ( $88 \pm$ $4 \%$ ) compared to the Tryne area ( $82 \pm 7 \%$ ) (post 1980), at least partially because retagging effort was greater in Long Fjord (Green et al. 1995). At McMurdo Sound, apparent survival rates differed between breeding states $(91 \pm 3 \%$ for breeders and $94 \pm 2 \%$ for nonbreeders), and were higher (probably more realistic) than at the Vestfold Hills at least partially because the estimates from McMurdo Sound were corrected for tag loss.

\section{Life history strategy}

We recognise that Weddell seals maintain relatively high and stable survival rates for long life (Cameron \& Siniff 2004) and multiple reproductive opportunities, only some of which are realised. This strategy is typical of Antarctic marine predators. Southern fulmars, Adelie penguins and Antarctic fur seals Arctocephalus 
gazella, for example, are also long-lived with timevarying reproductive success (Whitehead et al. 1990, Jenouvrier et al. 2003, 2005, Forcada et al. 2005). This life history generally corresponds with variable environments (Ferguson \& Lariviere 2002). Indeed, physical conditions in the Southern Ocean are highly variable, with cyclic changes in the circumpolar movement of atmosphere and ocean linked to ENSO and other principal modes of variability (Turner 2004).

One theoretical description of the Weddell seal's lifehistory is 'bet hedging' (Stearns 1992), i.e. spreading out of reproductive bouts so that individuals sample a number of environments and thereby increase the probability of reproducing in a good season, whereby fitness consequences of greater pup survival are realized. However, we suggest that Weddell seal investment is more prudent than simply randomly sampling a variable environment. Based on temporal variability in reproductive rate, combined with lack of evidence for costs of reproduction, we infer that Weddell seals prudently select years for reproduction, pre-empting challenging reproductive attempts.

Phocid seals derive the majority of energy for lactation from maternal body stores (see Wheatley et al. 2006). Thus there is potential to physiologically assess the probability of achieving viable weaning mass for each pup, during pregnancy, on the basis of maternal nutritional state (Trites \& Donnelly 2003). Evidence suggests that when foraging conditions are challenging, some species tend to terminate pregnancy and thereby conserve energy, as opposed to proceeding with reproduction and depleting body stores when there is minimal chance of producing a viable pup (Boyd 2000). Terminal sampling at various stages of gestation has provided unequivocal evidence of intrauterine mortality for Weddell seals (Testa \& Siniff 1987).

\section{Costs of reproduction}

Hadley et al. (2007) found evidence for Weddell seals, like southern elephant seals (McMahon et al. 2005), incurring survival costs of reproduction. Thus they concluded that Weddell seals are not prudent parents and instead follow the flexible strategy hypothesis, which originally was proposed as a response to variable environments (Reid 1987). However, Hadley et al. (2007) also found that the magnitude of survival costs was time-invariant, regardless of environmental conditions, which is somewhat at odds with their hypothesis. Considering the Weddell seal's low rates of first-year survival, there may be strong selective pressure for mothers to invest in lactation to such an extent that they incur survival costs. However, no survival or reproductive costs were detected for Weddell seal mothers further north at the Vestfold Hills. There may be estimation problems; Hadley et al. (2007) incorporated age and other variables in their models and reported that it was difficult to obtain precise estimates for the time-varying model given the large increase in parameters. Future work on Weddell seals may benefit from better information on the actual covariates associated with variation. Such random-effects models would be more parsimonious than models that are simply time-varying.

Even so, costs of reproduction are notoriously difficult to measure. Evidence of costs can be confounded by heterogeneity in individual quality because individuals with greater fitness are more likely to survive and to breed in consecutive years, and this counterbalances evidence for individuals not reproducing in consecutive years and not surviving when they have reproduced. Wheatley et al. (2006) report clear evidence for individual variation in measures of fitness for Weddell seals. Therefore, conclusions are limited to stating that a 'recovery year' post reproduction is not a dominant life-history strategy for Weddell seals and that Weddell seals seem to regulate energetic investment in reproduction prior to birth so as to conserve energy and avoid time-varying costs. Their reproductive strategy appears to confer the option to reproduce in any year that conditions are suitable.

\section{Indices of foraging success}

Incorporating all research to date, we suggest that rather than adopting a single strategy, the Weddell seal's response to environmental variability is multifaceted. It has been shown that pup mass and maternal condition at weaning vary inter-annually with potential consequences for pup survival and recruitment (Wheatley et al. 2006, Proffitt et al. 2007). We emphasize here that Weddell seals also regulate energetic investment prior to birth. Seasonal availability of prey may determine which strategy a female adopts. Poor foraging early on may result in loss of pup; poor foraging later on may mean they carry it to term. The energetic cost of early versus late-term termination would be offset by the option to proceed with pregnancy should foraging conditions change. It is highly likely that there are individual differences in the physiological threshold for termination. If poor foraging occurs later on and a proportion of the population still reproduces, then those individuals may incur costs for future reproduction and survival that are not apparent at the population level.

In the past, reproductive rate has been difficult to quantify and not well understood (Testa et al. 1990), so 
maternal post-partum mass, weaning mass and firstyear survival have been used to index inter-annual variation in maternal condition of Weddell seals (Hastings et al. 1999, Wheatley et al. 2006, Proffitt et al. 2007). However, if most individuals reproduce in favourable years and only a sub-sample biased toward high quality individuals reproduce in poor years, then there is inter-annual variation in the sample of females producing pups that is not independent of maternal condition. Thus, comparison of body condition between years may be biased towards animals in good condition, for example. Some of the indices of environment may be more precise and interpretable than others. What needs to be evaluated is the amount of additional information obtained from each index with regard to the disturbance caused and logistical demands of collecting the data. At this stage, we conclude that modeling methods now enable accurate estimates of reproductive rate from tag and re-sight data and that this parameter is an integral component of modeling maternal foraging success.

\section{Interpreting the time series}

Demographic rates are quantitative measures of population status and it is pertinent to understand their fluctuations. A powerful way of doing this is through correlation analysis incorporating environmental time series hypothesized a priori to cause the demographic response. Monitoring studies generally assume reproductive output is determined by availability and quality of food. However, in Antarctica there are few time series pertaining to marine productivity and mechanisms involving ocean currents, stratification and several trophic layers in response to and simultaneous with climate forcing are potentially too complex to infer (Constable et al. 2003). Furthermore, Weddell seals at the Vestfold Hills eat multiple prey types and may compensate for declining abundance of one species by switching to other species or increasing foraging effort (Lake et al. 2003), which makes a linear relationship between seal demographics and prey availability unlikely. A linear response to prey abundance is particularly unlikely where access to prey is limited by sea ice. Indices of sea ice can be incorporated in explanatory models. However, at the Vestfold Hills it may be specific details of sea ice, such as fastice cover, which influence winter foraging range because at least a proportion of the population uses fast ice as resting platforms from which to commute to forage in more open water (Lake et al. 2005, 2006). Given the large range of possible drivers, knowledge of predator physiology and foraging behaviour is essential to form hypotheses a priori regarding which envi- ronmental parameters correlate with reproduction. At this stage, no environmental parameters have been tested, but some of our results do pertain to formulating hypotheses by defining the temporal and spatial resolution of the reproductive index.

Regarding the time period over which reproductive rate is determined, the lack of evidence for reproductive costs suggests that reproductive rate is determined post December, when the previous year's pups are weaned, and before October, when the next pup cohort is born. Thus reproductive rate could reflect conditions from January to September and in this way, could be specific to the year of measurement. At this stage, there are no data for finer resolution; Bowen et al. (1981) suggested that phocid females assess body condition continually throughout pregnancy and this hypothesis is supported by terminal sampling of Weddell seals at various stages of gestation (Testa \& Siniff 1987). However, Boyd (1991) proposed that, following mating and a 3 mo diapause, implantation is when environmental factors, such as nutrition and climate, exert their greatest influence. That hypothesis is consistent with the multi-faceted response of Weddell seals to environmental variation.

Spatial resolution of the time series will become clear as tracking and dive data accumulate. At this stage, we know that Weddell seals forage over small scales compared to other land-based predators in Antarctica (tens or hundreds of kilometers as compared to thousands) (Lake et al. 2003, 2005, 2006). Therefore the reproductive time series is probably indicative of quite local conditions and sensitive to small- to medium-scale environmental anomalies within that area (movement of upwelling zones for example). The implication for monitoring is that while the area of reference is welldefined, it is necessary to monitor many populations to determine whether local conditions are in synchrony on a broader scale and thus interpret the spatial scale of forcing.

\section{Multiple time series}

Croxall et al. (2002) examined geographical inconsistencies in various Antarctic predator time series. They found that Weddell seals at McMurdo Sound experienced low reproductive rates in 1977-78 and again in 1983-84, as did black-browed albatross, macaroni penguins and gentoo penguins at South Georgia. They concluded from the geographical breadth of that signal that the same broad-scale mechanism was responsible for depression at all locations, thereby implicating large-scale atmospheric or oceanic forcing (Croxall et al. 2002). Linking events could be regarded as special pleading, but we do note that a perturbation 
around the same time was evident in both the reproduction time series from Weddell seals at the Vestfold Hills and the reproductive parameters of Adelie penguins at that same location (Whitehead et al. 1990). Those signals did occur following a strong El Niño event in equatorial regions (Fig. 4).

In contrast, low reproductive rates were experienced by Weddell seals throughout the 1990s at the Vestfold Hills but not at McMurdo Sound (Hadley et al. 2007). If the Vestfold Hills signal was in response to El Niño forcing, then the geographical scale of forcing was not to the extent of the entire Southern Ocean. Ultimately, it is local phenomena that directly affect biota, not broad-scale mechanisms. The local effect may be highly specific. For example, thermal inertia of the ocean may delay transition from one state to another. Conversely, small physical changes can cascade quickly through marine food webs; wind-driven mixing in the euphotic zone, for example, can quickly dilute the concentration of phytoplankton (Chavez et al. 2003).

There was a strong perturbation in the 1990s in predator populations at the Antarctic Peninsula that has been associated with krill cohorts senescing without reproduction as a consequence of many years of reduced sea ice area (Fraser \& Hofmann 2003, Siegel 2005). Despite potential for that perturbation to move around the continent with the Antarctic Circumpolar Current (Siegel 2005), a 1990s low was not evident in time series for Adelie penguins at Mawson, Terre Adelie or McMurdo Sound (Woehler et al. 2002, Jenouvrier et al. 2005). Monitoring of Adelie penguins at the Vestfold Hills stopped in 1989 (Woehler et al. 2002), so a 1990s event specific to Prydz Bay cannot be confirmed. This highlights the value of monitoring several species at various locations and maintaining programs over time for insightful interpretation of timeseries data.

\section{CONCLUSIONS}

The value of monitoring programs increases exponentially over time. The mark and re-sight program of Weddell seals at the Vestfold Hills is one of the longest time-series pertaining to Antarctic ecosystems. International cohesion in Weddell seal research has resulted in directly comparable datasets from opposite sides of Antarctica. Mark and re-sight observations of individual animals are one of the best sources of data for population models and the method is particularly appropriate for Weddell seals because they are readily approachable and form discrete populations in welldefined areas, such as Long Fjord at the Vestfold Hills. Reproductive rate is presented as an index that cap- tures and condenses information from this predator's perspective of its prey field. Breaks in monitoring can be incorporated in reproduction models. What is required is a group of marked females maintained over time and re-sighted when deemed appropriate in sequential years. With a rigorous baseline of observations already established, future monitoring is well placed to detect changes over time. Links with the ecosystem will be deciphered as tracking and dive data reveal the foraging strategies of this species.

Acknowledgements. Many people gave time to the mark and re-sight program and as a group we thank them sincerely. In particular, we recognize the years of work of K. Green, D. Watts and J. van den Hoff. All field procedures were carried out under the terms of the Antarctic Treaty Permit System. Logistical support was from the Australian Antarctic Scientific Advisory Committee and the Australian Antarctic Division.

\section{LITERATURE CITED}

Bowen D, Capstick C, Sergeant D (1981) Temporal changes in the reproductive potential of female harp seals (Pagophilus groenlandicus). Can J Fish Aquat Sci 38: 495-503

Boyd IL (1991) Environmental and physiological factors controlling the reproductive cycles of pinnipeds. Can J Zool 69:1135-1148

Boyd IL (2000) State-dependent fertility in pinnipeds: contrasting capital and income breeders. Funct Ecol 14: 623-630

Burnham KP, Anderson DR (1992) Data-based selection of an appropriate biological model: the key to modern data analysis. In: McCullough DR, Barrett RH (eds) Wildlife 2001: populations. Springer, Berlin, p 16-30

Cameron MF, Siniff DB (2004) Age-specific survival, abundance, and immigration rates of a Weddell seal (Leptonychotes weddellii) population in McMurdo Sound, Antarctica. Can J Zool 82:601-615

Chavez F, Ryan J, Lluch-Cota S, Niquen M (2003) From anchovies to sardines and back: Mulitdecadal change in the Pacific Ocean. Science 299:217-221

Constable AJ, Nicol S, Strutton PG (2003) Southern Ocean productivity in relation to spatial and temporal variation in the physical environment. J Geophys Res 108:C4-8079

Croxall JP, Hiby L (1983) Fecundity, survival and site fidelity in Weddell seals, Leptonychotes weddelli. J Appl Ecol 20: $19-32$

Croxall JP, Trathan P, Murphy E (2002) Environmental change and Antarctic seabird populations. Science 297: 1510-1514

Ferguson S, Lariviere S (2002) Can comparing life histories help conserve carnivores? Anim Conserv 5:1-12

Forcada J, Trathan PN, Reid K, Murphy EJ (2005) The effects of global climate variability in pup production of Antarctic fur seals. Ecology 86:2408-2417

> Fraser WR, Hofmann EE (2003) A predator's perspective on causal links between climate change, physical forcing and ecosystem response. Mar Ecol Prog Ser 265:1-15

Green K, Burton HR, Watts DJ (1995) Studies of the Weddell seal in the Vestfold Hills, East Antarctica. In: ANARE Research Note 93. Australian Antarctic Division, Kingston, p 64 
Hadley G, Rotella J, Garrott R (2007) Evaluation of reproductive costs for Weddell seals in Erebus Bay, Antarctica. J Anim Ecol 76:448-458

Hastings K, Testa J, Rexstad E (1999) Interannual variation in survival of juvenile Weddell seals (Leptonychotes weddelli) from McMurdo Sound, Antarctica: effects of cohort, sex and age. J Zool (Lond) 248:307-323

Jenouvrier S, Barbraud C, Weimerskirch H (2003) Effects of climate variability on the temporal population dynamics of southern fulmars. J Anim Ecol 72:576-587

Jenouvrier S, Barbraud C, Weimerskirch H (2005) Sea ice affects the population dynamics of Adelie penguins in Terre Adelie. Polar Biol. 29(5):413-423

Kwok R, Comiso J (2002) Southern ocean climate and sea ice anomalies associated with the Southern Oscillation. J Clim 15:487-501

Lake SE (2007) Response to change in the environment: Population dynamics of Weddell seals in East Antarctica. PhD thesis, University of Tasmania, Hobart

Lake SE, Burton HR, van den Hoff J (2003) Regional, temporal and fine-scale spatial variation in Weddell seal diet at four coastal locations in east Antarctica. Mar Ecol Prog Ser 254:293-305

Lake SE, Wotherspoon S, Burton H (2005) Spatial utilisation of fast-ice by Weddell seals Leptonychotes weddelli during winter. Ecography 28:295-306

Lake SE, Burton H, Wotherspoon S (2006) Movements of Weddell seals during the winter months. Polar Biol 29: 270-279

McMahon C, Bester M, Burton H, Hindell M, Bradshaw C (2005) Population status, trends and a re-examination of the hypotheses explaining recent declines of the southern elephant seal Mirounga leonina. Mammal Rev 35:82-100

Neter J, Wasserman W, Kutner MH (1990) Applied linear statistical models, 3rd edn., Homewood, IL

Nichols JD, Hines JE, Pollock KH, Hinz RL, Link WA (1994) Estimating breeding proportions and testing hypotheses about costs of reproduction with capture-recapture data. Ecology 75:2052-2065

Proffitt KM, Garrott RA, Rotella JJ, Siniff DB, Testa JW (2007) Exploring linkages between abiotic oceanographic processes and a top-trophic predator in an Antarctic ecosystem. Ecosystems 10:120-127

Reid WV (1987) The cost of reproduction in Glaucous-winged gull. Oecologia 74:458-467

Siegel V (2005) Distribution and population dynamics of

Initial editorial responsibility: Howard Browman, Storebø,

Norway; Final editorial responsibility: Matthias Seaman,

Oldendorf/Luhe, Germany
Euphausia superba: summary of recent findings. Polar Biol 29:1-22

Siniff DB, DeMaster D, Hofman R, Eberhardt L (1977) An analysis of the dynamics of a Weddell seal population. Ecol Monogr 47(3):319-335

Stearns S (1992) The evolution of life histories. Oxford University Press, Oxford

Testa JW, Siniff DB (1987) Population dynamics of Weddell seals (Leptonychotes weddelli) in McMurdo Sound, Antarctica. Ecol Monogr 57:149-165

Testa JW, Siniff DB, Croxall JP, Burton HR (1990) A comparison of reproductive parameters among three populations of Weddell seals (Leptonychotes weddellii). J Anim Ecol 59:1165-1175

Testa JW, Oehlert G, Ainley DG, Bengtson JL, Siniff DB, Laws RM, Rounsevell D (1991) Temporal variability in Antarctic marine ecosystems: periodic fluctuations in the phocid seals. Can J Fish Aquat Sci 48:631-639

Trillmich F, Ono K (1991) Pinnipeds and El Niño: responses to environmental stress. Springer Verlag, Berlin, p 206-218

Trites A, Donnelly C (2003) The decline of Steller sea lions Eumetopias jubatus in Alaska: a review of the nutritional stress hypothesis. Mammal Rev 33:3-28

Turner J (2004) The El Niño-southern oscillation and Antarctica. Int J Climatol 24:1-31

Watkins A, Simmonds I (2000) Current trends in Antarctic sea ice: the 1990s impact on a short climatology. J Clim 13(24): 4441-4451

- Wheatley K, Bradshaw C, Davis L, Harcourt R, Hindell M (2006) Influence of maternal mass and condition on energy transfer in Weddell seals. J Anim Ecol 75: 724-733

White W, Peterson R (1996) An Antarctic circumpolar wave in surface pressure, wind temperature and sea-ice extent. Nature 380:699-702

Whitehead MD, Johnstone GW, Burton HR (1990) Annual fluctuations in productivity and breeding success of Adelie penguins and fulmarine petrels in Prydz Bay, East Antarctica. In: Kerry KR, Hempel G (eds) Antarctic ecosystems: ecological change and conservation, Springer, Berlin, p 215-223

Woehler EJ, Cooper J, Croxall J, Fraser W and others (2002) A statistical assessment of the status and trends of Antarctic and subantarctic seabirds. Report on SCAR BBS Workshop on Southern Ocean seabird populations, Bozeman, MT, May 17-21, 1999. SCAR, Cambridge

Submitted: September 4, 2007; Accepted: April 1, 2008

Proofs received from author(s): July 27, 2008 